\title{
Convergencia a Normas Internacionales de Contabilidad para el Sector Público (Nicsp): comparativo de los modelos de Colombia y Chile
}

\author{
Convergence of International Accounting Standards in the Public Sector (IPSAS): A Comparison between \\ Colombian and Chilean Models \\ Convergência às Normas Internacionais de Contabilidade para o Setor Público (Nicsp): comparativo dos \\ modelos da Colômbia e do Chile
}

Oscar Dario Velásquez Graciano

Politécnico Colombiano Jaime Isaza Cadavid, Colombia odvelasquez@elpoli.edu.co

ORCID: http://orcid.org/0000-0001-7565-4381

DOI: https://doi.org/10.11144/Javeriana.cc18-45.cnic Redalyc: http://www.redalyc.org/articulo.oa? id $=151556994002$

José Vidal Pérez Morales

Corporación Universitaria Remington, Colombia

Fecha de recepción: 12 Junio 2017 Fecha de aprobación: 02 Marzo 2018

\section{Resumen:}

El presente artículo tiene como objetivo exteriorizar los adelantos que se vienen generando en algunos países de Latinoamérica, especialmente en Colombia y Chile, con el proceso de convergencia a las Normas Internacionales de Información Financiera para el Sector Público (Nicsp), expedidas por el Consejo de Normas Internacionales de Contabilidad del Sector Público (International Public Accounting Standards Board/Ipsasb), de la Federación Internacional de Contadores (International Federation of Accountants /IFAC), organismo responsable de expedir las normas contables para ese sector. Los garantes de esos cambios normativos, en el caso colombiano, son el Ministerio de Hacienda y Crédito Público, por intermedio de la Unidad Administrativa de la Contaduría General de la Nación; y en el de Chile, la Contraloría General de la República de Chile. Para el logro del objetivo se utilizará la información legal y contable de los organismos reguladores de cada país, artículos relacionados con Normas Internacionales de Contabilidad para el Sector Público y el portal de la IFAC, entre otros.

Palabras clave: Norma Internacional de Contabilidad para el Sector Público (Nicsp), entidad de gobierno, marco conceptual, reconocimiento, medición, revelación, catálogo de cuentas.

\section{Abstract:}

This article aims to make known the advances being developed in some Latin-American countries, particularly in Colombia and Chile, through the process of convergence with the International Financial Reporting Standards (IFRS) in the Public Sector as issued by the International Sector Public Accounting Standards Board (IPSASB ${ }^{\circ}$ ), making part of the International Federation of Accountants (IFAC), an institution in charge of issuing the accounting standards for the public sector. The institutions guaranteeing these normative changes are, in the Colombian case, the Ministry of the Treasury and Public Credit with its Administrative Unit of the Nation's General Accounting Office; and in the Chilean case, the General Comptroller's Office of the Republic of Chile. To attain the aim, this work will use the legal and accounting information from the regulatory institutions in each country, some articles related to the International Public Sector Accounting Standards, the IFAC website, among other things. Keywords: International Public Sector Accounting Standards (IPSAS), governmental entity, conceptual framework, recognition, measuring, disclosure, accounts catalogue.

\section{Resumo:}

O presente artigo objetiva exteriorizar os avanços gerados em alguns países de América Latina, especialmente na Colômbia e no Chile, com o processo de convergência às Normas Internacionais de Relato Financeiro para o Setor Público (Nicsp), emitidas pelo Conselho de Normas Internacionais de Contabilidade do Setor Público (International Public Accounting Standards Board/ Ipsasb), da Federação Internacional de Contadores (International Federation of Accountants /IFAC), organismo responsável de emitir as normas contábeis para o setor. Os garantes de tais mudanças regulatórias, no caso colombiano, é o Ministério de Fazenda e Crédito Público, através da Unidade Administrativa da Contaduría General de la Nación; e no de Chile, a Contraloría General de la República de Chile. Para conseguir o objetivo utilizam-se relatórios legais e contábeis de organismos reguladores de cada país, artigos relacionados com Normas Internacionais de Contabilidade para o Setor Público e o portal da IFAC, dentre outros.

Palavras-chave: Regulamento Internacional de Contabilidade para o Setor Público (Nicsp), entidade de governo, quadro conceptual, reconhecimento, aferição, revelação, catálogo de contas. 


\section{Introducción}

La contabilidad pública, bajo el principio de devengo o acumulación, se ha constituido en un sistema de información contable relevante para los países de América Latina, por cuanto contribuyen al mejoramiento de la transparencia en el manejo de los recursos públicos, la adecuada toma de decisiones, la rendición de cuentas para los diferentes usuarios de la información que requieren de ella para la evaluación y al ejercicio de control de los recursos por parte de los usuarios de carácter gubernamental o no gubernamental que interactúan con ellos.

Con la implementación de las Nicsp, el reconocimiento, la medición, la presentación y la revelación de los hechos económicos, financieros, sociales y ambientales cambia la forma de analizar los estados financieros, los informes complementarios, los indicadores para el cumplimiento de los objetivos, la toma de decisiones y la rendición de la información financiera para los usuarios de ella.

El presente trabajo está centrado en temas relacionados con los fundamentos históricos de la IFAC y las Nicsp. También incluye un análisis comparativo de los marcos conceptuales más recientes expedidos por cada país en lo relacionado con los objetivos, las definiciones de los principales elementos que conforman los estados financieros, las características, los principios de contabilidad y los criterios de valoración, el reconocimiento del deterioro de los activos y los respectivos catálogos generales de cuentas que les aplica actualmente, utilizando como metodología la elaboración de matrices de comparación en los que se plasman los aspectos fundamentales del marco conceptual, el ámbito de aplicación y los reguladores de cada región, entre otros, con sus respectivos comentarios para que los usuarios puedan identificar aspectos de implementación de las normas internacionales de contabilidad pública en cada país.

Esta información consolidada servirá de base para identificar elementos diferenciadores entre los marcos normativos contables de cada país, desde el punto de vista conceptual e instrumental, con miras a una adecuada aplicación en las entidades del sector público de cada uno de ellos.

Los motivos para la selección de los dos países obedecen a que son pioneros en la implementación de las Nicsp en América Latina y a que utilizaron la adopción indirecta sobre la base de leyes nacionales expedidas en cada uno.

\section{Origen de la IFAC y de las normas internacionales de contabilidad pública para entidades de gobierno}

La IFAC fue fundada en 1977 con el fin de trabajar por el interés público, fortalecer la profesión contable, impulsar la observancia de las normas internacionales de contabilidad en los países del mundo, fomentar los valores de la transparencia mediante el diseño y elaboración del código de ética y promover las normas internacionales de auditoría para el sector de la economía real y del sector público, al fijar pautas para las normas internacionales de educación contable y prestar servicios de asesoría y aseguramiento (IFAC, 2005).

En la actualidad, la IFAC está conformada por 179 miembros y/o asociados que representan a 130 países, constituyendo aproximadamente 2,5 millones de profesionales de la contabilidad a nivel mundial. Dentro de la estructura de esta entidad se encuentra la Junta de Normas Internacionales de Contabilidad del Sector público (Ipsasb por sus siglas en inglés), responsable del desarrollo de las normas internacionales de contabilidad para el sector público (Nicsp), las cuales se constituyen en la base para su implementación en los diferentes gobiernos del mundo (IFAC, 2005).

El Ipsasb se orienta "al interés general con orientación de sectores sociales" (Mejía et al., 2006), con el fin de que este usuario tenga acceso a la información contable pública y pueda ejercer control social a la gestión del gobernante. 


\section{Contexto teórico y conceptual}

El contexto teórico y conceptual se fundamenta en los marcos regulatorios contables establecidos en cada país, las respectivas constituciones políticas, los documentos emitidos por entidades internacionales contables y los informes ejecutivos de organismos financieros internacionales.

En la literatura contable no se encontraron escritos relacionados con comparativos de implementación de normas internacionales de contabilidad para el sector público (Nicsp) entre ambos países, dado que su proceso de aprobación de la regulación contable empezó en el año 2015, su aplicación en los años 2016 y 2018, y no existen resultados e impactos generados en su adopción.

En el trabajo aparecen definiciones de los elementos que van a ser comparados entre ambos países, extraídos de los marcos normativos contables, de organizaciones internacionales como la IFAC, el Fondo Monetario Internacional (FMI), organismos reguladores de cada país y referencias de autores que han escrito sobre la contabilidad pública bajo normas internacionales de contabilidad. Los conceptos que fueron objeto de comparación entre los países son los siguientes: marco conceptual, elementos de los estados financieros, objetivos, características y gobierno general, entre otros, sobre los cuales se estructuró el desarrollo del trabajo. Adicionalmente, se hizo una revisión de la literatura generada por cada regulador contable, como la Contaduría General de la Nación y la Contraloría General de la República de Chile, con el fin de argumentar los elementos comparados de cada marco normativo contable bajo las Nicsp.

Este comparativo les permitirá a los usuarios de la información contable pública conocer en detalle aspectos teóricos, conceptuales e instrumentales para evaluar la situación financiera de las entidades de gobierno general, al momento que sean divulgados por los respectivos responsables de la información contable pública de cada país.

\section{Ámbito de aplicación de las Nicsp}

Con el fin de establecer las entidades del sector público obligadas a su aplicación, la IFAC se refiere al "sector gobierno" como las entidades conformadas por el gobierno nacional, las regionales (provincias y territorios) y las relacionadas con las mismas (agencias, juntas, y comisiones entre otras) (IFAC, 2004).

Con respecto a Colombia y Chile, en sus marcos normativos contables se define claramente el concepto de entidad de gobierno de la siguiente forma: 
TABLA 1

Definición de entidad de gobierno en Colombia y en Chile

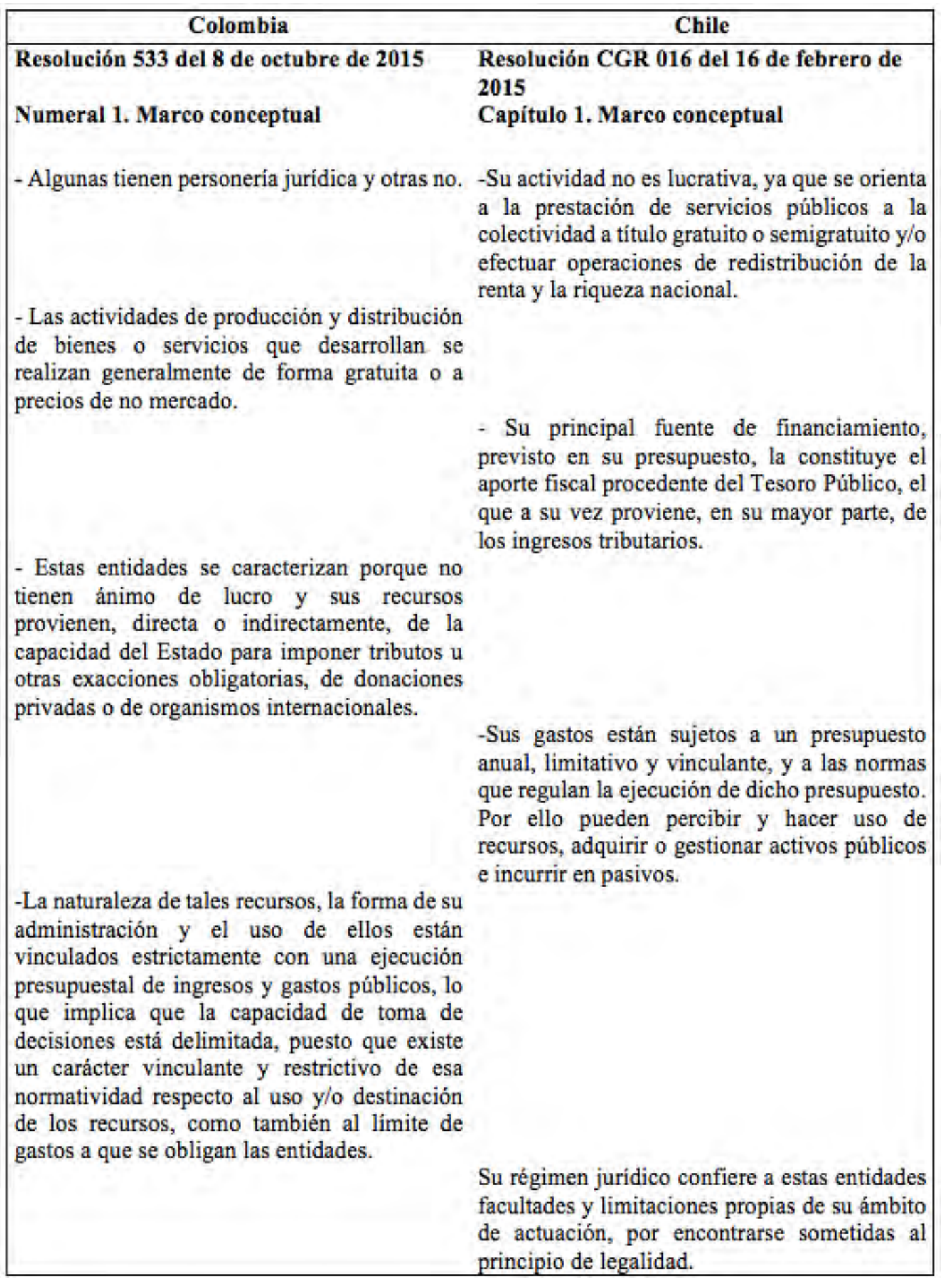


TABLA 1 (CONTINUACIÓN)

Definición de entidad de gobierno en Colombia y en Chile

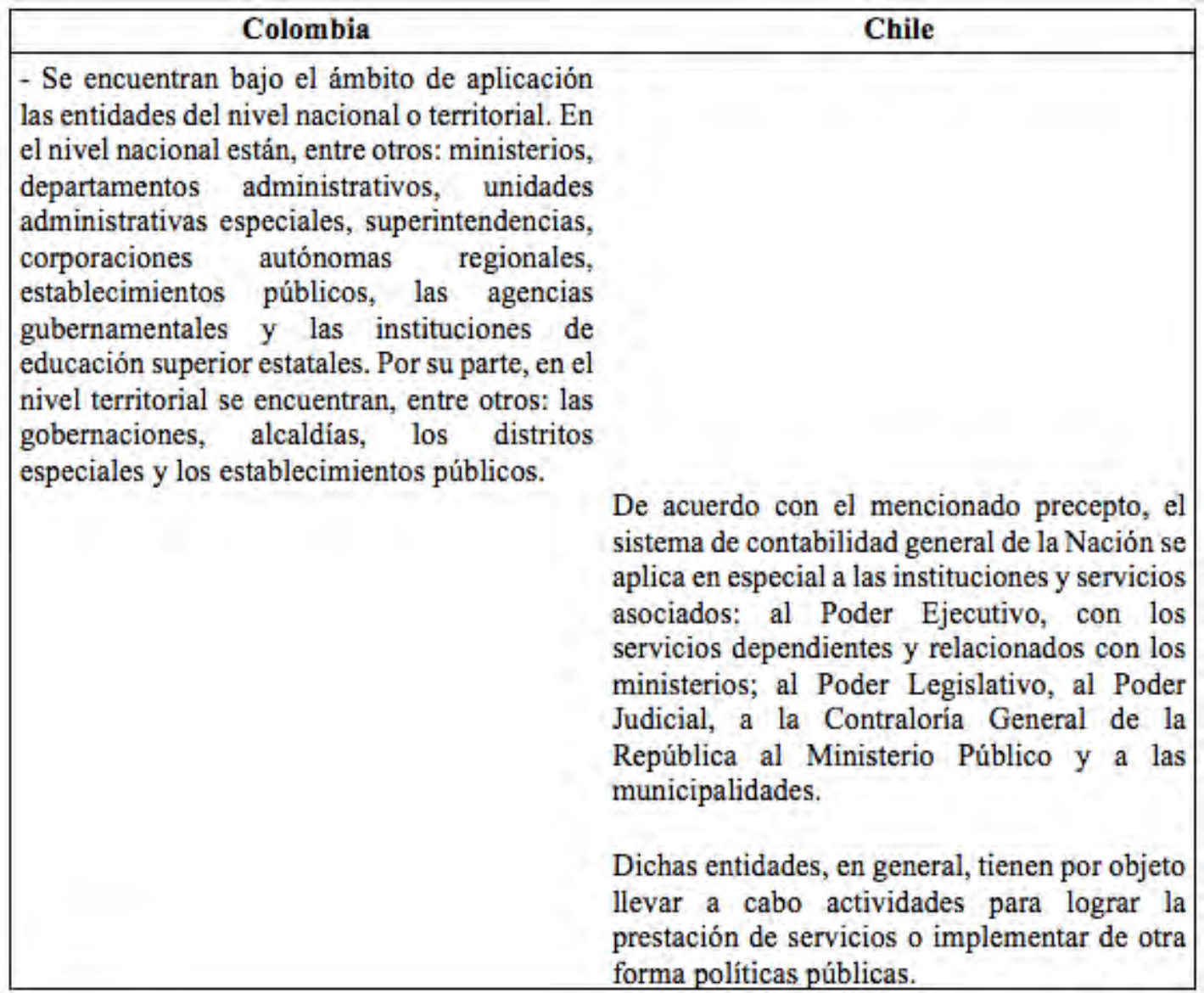

Fuente: elaboración propia. Resolución 533 del 8 de octubre de 2015 y la CGR 016 del 16 de febrero de 2015. 
Se observa en el comparativo que la definición de entidad de gobierno identifica las mismas características entre Colombia y Chile; para efectos de la implementación de las Nicsp, en el caso colombiano se expidió además la Ley 489 de 1998, por medio de la cual se dictan normas sobre la organización y funcionamiento de las entidades del orden nacional.

En el contexto del sector público, los dos países, desde su estructura administrativa y según la Constitución política de cada país, contemplan los poderes ejecutivo, legislativo y judicial, y para el ámbito de aplicación de las Nicsp se consideraron las entidades de gobierno del orden central nacional y territorial, organismos de control, algunos servicios descentralizados, instituciones de educación superior y órganos autónomos establecidos en cada región.

Esta caracterización les permitirá a los gobiernos tener un mayor control de los recursos públicos y su adecuado manejo para efectos de rendir cuentas a los diferentes usuarios mediante la presentación y revelación de los estados financieros de las entidades llamadas a cumplir con los fines sociales del Estado y será de interés para los usuarios que quieren conocer el uso de sus tributos y demás recursos aportados al Estado y hacer comparativos desde lo local o lo internacional. Para efectos de la convergencia a las Nicsp y a las NIIF en el sector público colombiano, la Contaduría General de la Nación identificó las siguientes entidades pública, con fundamento en la Clasificación de entidades del sector público colombiano, para la elaboración de las Estadísticas de Finanzas Públicas de la Comisión Intersectorial de Estadísticas de Finanzas Públicas (Ciefp):

TABLA 2

Sector público colombiano

\begin{tabular}{|l|l|}
\hline Sector & Subsector \\
\hline Gobierno general & $\begin{array}{l}\text { Gobierno central } \\
\text { Gobierno departamental } \\
\text { Gobierno municipal } \\
\text { Seguridad social }\end{array}$ \\
\hline $\begin{array}{l}\text { Sociedades } \\
\text { financieras }\end{array}$ & $\begin{array}{l}\text { Banco central } \\
\text { Otras sociedades de depósito } \\
\text { Otros intermediarios financieros } \\
\text { Fondos de cesantía } \\
\text { Otros auxiliares financieros } \\
\text { Sociedades de pensiones y cesantía } \\
\text { Compañias de seguros } \\
\text { EPS salud } \\
\text { Otros seguros sociales en salud } \\
\text { Fondos de pensiones }\end{array}$ \\
\hline $\begin{array}{l}\text { Empresas no } \\
\text { financieras } \\
\text { públicas }\end{array}$ & $\begin{array}{l}\text { Empresas industriales y comerciales } \\
\text { Sociedades de economía mixta } \\
\text { Empresas de servicios públicos } \\
\text { domiciliarios } \\
\text { Empresas sociales del Estado }\end{array}$ \\
\hline
\end{tabular}


La tabla anterior permite describir la clasificación de las entidades públicas en el sector público colombiano, para efectos de la asignación de los marcos normativos contables bajo normas internacionales de contabilidad expedidos por la Contaduría General de la Nación y cuya fuente proviene del Manual de estadísticas de las finanzas públicas 2001. Otros factores tenidos en cuenta en esta clasificación es el criterio de entidad contable pública, dado que se caracterizan por estar en un entorno jurídico, económico y social (Contaduría General de la Nación, 2015).

El sector público chileno contempla dentro de su estructura política a sectores y subsectores clasificados en entidades de gobierno general y empresas públicas, acorde con el Manual de estadísticas de finanzas públicas del FMI, que se constituyeron en fuente de aplicación para la implementación de las Nicsp en Chile.

Lo anterior permite establecer que Colombia y Chile contemplan una estructura similar en la composición del sector público; para efectos de la adopción indirecta de las Nicsp se identificó también el concepto de entidad contable y sus entornos jurídico, económico y social (Contraloría General de la República de Chile, 2015).

\section{Reguladores contables en Colombia y Chile}

Para el caso de Colombia, la responsabilidad de uniformar, consolidar y centralizar la información contable pública está a cargo de la Contaduría General de la Nación, unidad administrativa adscrita al Ministerio de Hacienda y Crédito, perteneciente a la rama del poder ejecutivo, creada mediante la Ley 298 de 1996, ligada a la figura del Contador General de la Nación, cuyas disposiciones normativas están representadas en resoluciones, cartas circulares, circulares externas e instructivos, entre otros (Congreso de la República, 1996). Este proceso regulatorio surge a partir del artículo 354 de la Constitución Política de 1991, desarrollado por la Ley 298 de 1996 y la Sentencia C-487 de 1997 de la Corte Constitucional, que declaró exequible esta norma, con algunas excepciones relativas a los requisitos para ejercer el cargo de contador general en esta nación.

Con estas facultades, la Contaduría General de la Nación, como entidad reguladora, expide el Plan General de Contabilidad Pública (PGCP) 2003, en el cual se resalta el proceso de planificación hacia estándares internacionales de contabilidad de la siguiente forma:

El sector público como responsable frente a la colectividad por el manejo y el control de ciertos recursos, debe asumir retos y renovar sus estructuras comunicativas con el fin de informar a la sociedad sobre el cumplimiento de sus funciones. Los Planes Generales de Contabilidad Pública (PGCP) son una respuesta a esos retos, y para abordarlos se debe tener en cuenta que su presencia no es ajena a un proceso de normalización contable, que se manifiesta de diferentes formas, dependiendo del país en el cual se desarrolla. (Contaduría General de la Nación, 2003, p. 11)

Con estas herramientas jurídicas, la Contaduría General de la Nación expidió en el 2013 el documento Estrategia de convergencia de la regulación contable pública hacia normas internacionales de información financiera (NIIF) y normas internacionales de contabilidad para el sector público (Nicsp), que contempla la propuesta de la política de regulación contable pública y cuya ejecución ha originado nuevos marcos normativos contables para las entidades del sector público colombiano (Contaduría General de la Nación, 2013).

Para el caso de Chile, la función de llevar la contabilidad general de la nación está a cargo de la Contraloría General de la República de Chile, cuyo órgano de control fiscal fue creado en armonía con el artículo 98 de la Constitución Política de 1980 y con la División de Análisis Contable, que expidió la Resolución CGR 54977 del 2010, relacionada con la presentación de los estados financieros y el plan de convergencia a normas internacionales de contabilidad para el sector público. 


\section{Marco constitucional de la contabilidad pública}

TABLA 3

Marco constitucional de la contabilidad pública

\begin{tabular}{ll}
\hline Colombia & Chile \\
\hline $\begin{array}{l}\text { Artículo } 354 \text { de la Constitución Política } \\
\text { de } 1991\end{array}$ & $\begin{array}{l}\text { Artículo } 98 \text { de la Constitución Política de } \\
1980\end{array}$
\end{tabular}

Habrá un Contador General, funcionario de la rama ejecutiva, quien llevará la contabilidad general de la Nación y consolidará esta con la de sus entidades descentralizadas territorialmente o por servicios, cualquiera que sea el orden al que pertenezcan, excepto lo referente a la ejecución del presupuesto, cuya competencia se atribuye a la Contraloría.

Corresponden al contador general las funciones de uniformar, centralizar y consolidar la contabilidad pública, elaborar el balance general y determinar las normas contables que deben regir en el pais, conforme a la ley.

Parágrafo. Seis meses después de concluido el año físcal, el Gobierno Nacional enviará al Congreso el balance de la Hacienda, auditado por la Contraloría General de la República, para su conocimiento y análisis.
Un organismo autónomo con el nombre de Contraloría General de la República ejercerá el control de la legalidad de los actos de la administración, fiscalizará el ingreso y la inversión de los fondos del fisco, de las municipalidades y de los demás organismos y servicios que determinen las leyes; examinará y juzgará las cuentas de las personas que tengan a su cargo bienes de esas entidades; llevará la contabilidad general de la Nación y desempeñará las demás funciones que le encomiende la ley orgánica constitucional respectiva.

El Contralor General de la República deberá tener a lo menos diez años de título de abogado, haber cumplido cuarenta años de edad y poseer las demás calidades necesarias para ser ciudadano con derecho a sufragio.

Será designado por el Presidente de la República con acuerdo del Senado adoptado por los tres quintos de sus miembros en ejercicio, por un período de ocho años, y no podrá ser designado para el período siguiente. Con todo, al cumplir 75 años de edad cesará en el cargo. CPR Art. $87^{\circ}$ D.O. 24.10 .1980 .

\footnotetext{
Fuente: elaboración propia. Artículo 354 de la Constitución Política de Colombia de 1991 y Artículo 98 de la Constitución Política de Chile de 1980.
}

Dentro del marco constitucional de la contabilidad pública que rige para cada uno de estos dos países existen diferencias en lo preceptuado en cada uno de esos artículos, tal como veremos a continuación:

Para el caso colombiano, la Constitución Política define claramente que habrá un Contador General, quien llevará la contabilidad de la Nación y la consolidará con la de sus entidades descentralizadas territorialmente o por servicios, cualquiera que sea el orden al que pertenezcan. 
Igualmente, el contador tendrá la función de certificar los estados financieros de las entidades que reportan información, toda vez que ese funcionario deberá tener título profesional de contador público.

A la par, la Contraloría General de la República es el órgano de control fiscal competente para vigilar lo referente con la ejecución del presupuesto y todo lo relacionado con el manejo de los recursos públicos. Además, audita los estados financieros que elaboran cada una de las entidades públicas, lo cual le permite dictaminar sobre la razonabilidad de estos.

En el caso chileno, el Contralor General de la República debe tener a lo menos diez años de haberse titulado de abogado y ejerce el control de la legalidad de los actos de la administración y fiscaliza el ingreso y la inversión de los fondos del fisco y de las municipalidades. Adicionalmente lleva la contabilidad general de la Nación.

Igualmente, le corresponde elaborar los estados consolidados sobre la situación presupuestaria, financiera y patrimonial, como también actualizar la normativa contable vigente para el sector público (Nicsp) emitida por la IFAC a través del Consejo de Normas Internacionales de Contabilidad para el Sector Público (Ipsasb), con el fin de mejorar la rendición de cuentas, la transparencia y la comparabilidad, fijando para ello criterios uniformes a nivel nacional.

En conclusión, cada una de estas dos instituciones tiene origen y fines diferentes; en el caso colombiano, la primera pertenece a la rama ejecutiva, y la segunda es un organismo de control que ejerce las funciones de control fiscal y de regulador en materia contable del sector público.

En el caso colombiano, la separación de competencias entre la Contaduría General y la Contraloría, a partir del Artículo 354 de la Constitución Política de 1991, le permite al Estado desconcentrar las funciones que estaban a cargo de la Contraloría General de la República, asignándole funciones de control fiscal y auditoría como ente autónomo de los poderes públicos y de regulador a la Contaduría General de la Nación, lo que contribuye a un mayor control y transparencia de los recursos públicos y al manejo de la información para los fines pertinentes.

\title{
Marco conceptual para la preparación y presentación de información financiera para las entidades de gobierno
}

El marco conceptual de la contabilidad para las entidades de gobierno en Colombia se define como:

\begin{abstract}
Los conceptos que se deben observar en la preparación y presentación de información financiera de propósito general de las entidades de gobierno, es decir, aquellos que pretenden cubrir las necesidades de usuarios que no están en condiciones de exigir informes a la medida de sus necesidades específicas de información. El Marco conceptual constituye la base para el desarrollo normativo, instrumental y doctrinal del regulador y, por ende, tiene valor normativo superior a la regulación que de él se deriva. Adicionalmente, el Marco conceptual tiene los siguientes objetivos: apoyar a los usuarios en la interpretación de la información financiera de las entidades de gobierno, ayudar a quienes preparan y presentan información financiera en el proceso de construcción de ésta y servir a los evaluadores de la información en el proceso de realización de juicios sobre la información financiera. (CGN, 2015, p. 1)
\end{abstract}

Adicionalmente, se tiene en cuenta que:

Un requisito sine qua non de un marco conceptual para su pertinencia, es que sea el producto de una reflexión realizada con el propósito de solucionar los problemas del entorno al cual va a servir el modelo a construir. Si esta condición no se cumple, el modelo que se elabore no va alcanzar el objetivo de promover información adecuada al servicio de los usuarios de ese entorno. (Colmenares et ál., 2008, p. 104)

Con estos elementos de un marco conceptual, los usuarios tendrán la posibilidad de tomar las decisiones que se ajusten a las necesidades de la entidad y evaluar la gestión del gobernante respectivo. 


\section{Objetivos de la información financiera}

Los objetivos de la información financiera buscan que esta sea útil, a partir de la satisfacción de las necesidades de sus usuarios. En ese sentido, el marco conceptual para las entidades de gobierno contempla los siguientes objetivos:

TABLA 4

Objetivos de la información financiera

\begin{tabular}{ll}
\hline Colombia & Chile \\
\hline $\begin{array}{l}\text { Resolución } 533 \text { del } 8 \text { de octubre de 2015. } \\
\text { Numeral 3. Marco conceptual }\end{array}$ & $\begin{array}{l}\text { Resolución CGR 016 del 16 de febrero de } \\
\mathbf{2 0 1 5} . \\
\text { Capítulo 1. Marco conceptual }\end{array}$ \\
$\begin{array}{l}\text { Rendición de cuentas. } \\
\text { Toma de decisiones. }\end{array}$ & $\begin{array}{l}\text { Proporcionar información sobre la entidad } \\
\text { que sea útil para los usuarios de los estados } \\
\text { Control. }\end{array}$ \\
& $\begin{array}{l}\text { financieros a efectos de rendición de } \\
\text { cuentas y toma de decisiones. }\end{array}$ \\
\hline
\end{tabular}

Fuente: elaboración propia. Resolución 533 del 8 de octubre de 2015 y CGR 016 del 16 de febrero de 2015.

Los marcos normativos contables de los dos países comparten objetivos comunes, salvo que Chile no incorpora el control como elemento adicional en este componente del marco conceptual, sin embargo, la Resolución CGR 016 de 2015, de la Contraloría General de la República de Chile, establece lo siguiente:

Esta información debe resultar de utilidad para los usuarios con el objeto de determinar el nivel de servicios que puede suministrar la entidad; su capacidad para cumplir adecuadamente sus objetivos; apoyar la evaluación de sus operaciones; favorecer el interés de los usuarios en la rendición de cuentas; y facilitar la evaluación de los logros alcanzados y de los recursos aplicados en la prestación de los servicios públicos. (Contraloría General de la República de Chile, 2015, p. 8)

Así mismo, la Contaduría General de la Nación requiere información para "los fines de consolidación y gestión de la información financiera del sector público, la cual es utilizada por otros usuarios en la toma de decisiones y en el ejercicio del control" (CGN, 2015, p. 2).

El cumplimiento de los objetivos por parte de ambos países genera confianza en los contribuyentes que aportan tributos al Estado, transparencia, eficiencia en el uso de los recursos y el ejercicio del control interno y externo de todos los usuarios, basados en la información financiera que divulga la entidad pública, en el campo de lo fiscal, social, administrativo y político, entre otros. 
Características cualitativas de la información financiera

TABLA 5

Características cualitativas de la información financiera

Colombia
Resolución 533 del 8 de octubre de 2015.
Numeral 4. Marco conceptual
Características fundamentales:
Relevancia: la información financiera
influye en los usuarios si es material y si
tiene valor predictivo, valor confirmatorio,
o ambos.

Representación fiel: se alcanza cuando la descripción del fenómeno es completa, neutral y libre de error significativo.

\section{De mejora:}

Verificabilidad: ayuda a asegurar, a los usuarios, que la información financiera representa fielmente los hechos económicos que pretende representar.
Chile

Resolución CGR 016 del 16 de febrero de 2015.

Capítulo 1. Marco conceptual

\section{Características cualitativas de la} información financiera: son una serie de atributos que hacen que la información contenida en los estados financieros sea útil para los usuarios.

Relevante y oportuna: la información será relevante para los usuarios si estos la pueden usar como ayuda para evaluar hechos pasados, presentes o futuros; o para confirmar o corregir observaciones que pudieran haber sido planteadas en evaluaciones anteriores. Para que la información sea relevante deberá, además, ser presentada con la debida oportunidad. 
TABLA 5 (CONTINUACIÓN)

Caracteristicas cualitativas de la información financiera

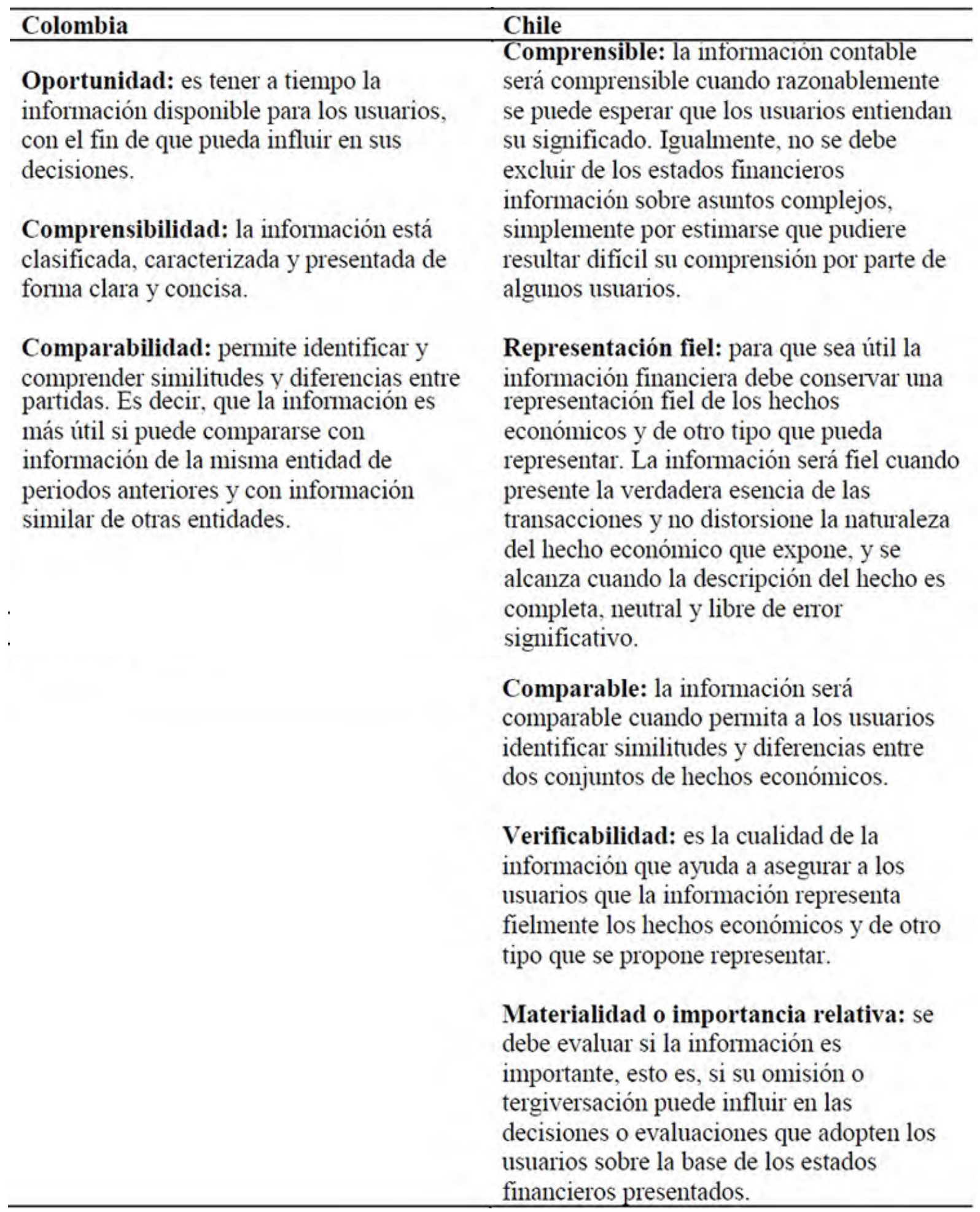

Fuente: elaboración propia. Resolución 533 del 8 de octubre de 2015 y CGR 016 del 16 de febrero de 2015. 
Los dos países comparten las mismas características cualitativas, salvo que la Contaduría General de la Nación, adicionalmente las clasificó en los grupos de fundamentales y de mejora, para efectos de reflejar la utilidad de la información que se requiere por los distintos usuarios.

Con el fin garantizar un mayor control desde lo contable y lo administrativo, es importante tener en cuenta, para la adecuada aplicación de la característica de materialidad, las necesidades de información de los usuarios, los topes o valores que permitan separar los activos en mayor y menor cuantía, y la recurrencia en el manejo de las operaciones económicas de una entidad de gobierno.

La adecuada aplicación de una característica contribuye a la utilidad de la información para los diferentes usuarios, dado que su generación se presenta en tiempo real, con calidad y confrontada entre periodos, lo que contribuye a una toma de decisión en la entidad que le permitirá hacer los ajustes necesarios para el logro de su cometido estatal.

\section{Principios de contabilidad}

Los principios de contabilidad son un conjunto de normas generales que sirven de guía contable para formular criterios referidos a la medición de hechos económicos que afectan el patrimonio de un ente público y que deben ser observados al momento de registrar e informar contablemente sobre los asuntos y actividades de personas naturales y/o jurídicas.

De conformidad con el artículo 68 de la Ley 43 de 1990, se entiende por principios o normas de contabilidad generalmente aceptados en Colombia:

Todo ese conjunto de actividades claves, que permiten: identificar, medir, clasificar, registrar, interpretar, analizar, evaluar e informar, las operaciones de un ente económico, en forma clara, completa y fidedigna.

Los principios hacen referencia a los criterios de medición de las transacciones, hechos y operaciones; al momento en el cual se realiza el reconocimiento contable; a la forma en que deben revelarse los hechos; a la continuidad del ente público; a la esencia de las transacciones y a la correlación entre ingresos, costos y gastos, entre otros, todo ello teniendo en cuenta las limitaciones propias que impone el entorno a las organizaciones. (Congreso de la República, 1990, Art. 68) 
TABLA 6

Principios de contabilidad

Colombia
Resolución 533 del 8 de octubre de 2015.
Numeral 5. Marco conceptual
Entidad en marcha: se presume que la
actividad de la entidad se lleva a cabo por
tiempo indefinido conforme a la ley o acto
de creación; por tal razón, la regulación
contable no está encaminada a determinar
su valor de liquidación. Si por
circunstancias exógenas o endógenas se
producen situaciones de transformación o
liquidación de una entidad, se deben
observar los criterios que se definan para
tal efecto.
Devengo: los hechos económicos se
reconocen en el momento en que suceden,
con independencia del instante en que se
produce el flujo de efectivo o equivalentes
al efectivo que se deriva de estos, es decir,
el reconocimiento se efectúa cuando surgen
los derechos y obligaciones, o cuando la
transacción u operación originada por el
hecho incide en los resultados del periodo.

Chile

Resolución CGR 016 del 16 de febrero de 2015.

Capítulo 1. Marco conceptual

\section{Gestión continuada}

Se presume, salvo prueba en contrario, que continúa la actividad de la entidad por tiempo indefinido conforme a la ley u otra disposición de su creación. Por tanto, la aplicación de las reglas contables no puede ir encaminada a determinar el valor de liquidación del patrimonio institucional.

Devengo: las transacciones y otros hechos económicos deben reconocerse en los registros contables cuando estos ocurren y no en el momento en que se produzca el flujo monetario o financiero derivado de aquellos. Los elementos reconocidos de acuerdo con este principio son activos, pasivos, patrimonio, ingresos y gastos patrimoniales e ingresos y gastos presupuestarios. 
TABLA 6 (CONTINUACIÓN)

Principios de contabilidad

Colombia
Esencia sobre forma: las transacciones y
otros hechos económicos de las entidades
se reconocen atendiendo a su esencia
económica, independientemente de la
forma legal que da origen a los mismos.
Asociación: el reconocimiento de los
ingresos con contraprestación está asociado
con los costos y gastos en los que se
incurre para producir tales ingresos.
Uniformidad: los criterios de
reconocimiento, medición, revelación y
presentación se mantienen en el tiempo y
se aplican a los elementos de los estados
financieros que tienen las mismas
características, en tanto no cambien los
supuestos que motivaron su elección. Si se
justifica un cambio en la aplicación de tales
criterios para mejorar la relevancia y la
representación fiel, la entidad debe revelar
los impactos de dichos cambios, de acuerdo
con lo establecido en las normas.

Chile

Imputación presupuestaria: la

imputación al presupuesto del ejercicio se efectuará atendiendo al origen del ingreso y al objeto del gasto y se realizará en la misma oportunidad en que se producen los hechos económicos, mediante el procedimiento técnico de integración contable presupuestaria que asocia el clasificador presupuestario de ingresos y gastos con el plan de cuentas contable. con los costos y gastos en los que se

Uniformidad: los criterios de reconocimiento, medición, revelación y presentación se mantienen en el tiempo y se aplican a los elementos de los estados financieros que tienen las mismas características, en tanto no cambien los supuestos que motivaron su elección. Si se justifica un cambio en la aplicación de tales criterios para mejorar la relevancia y la los impactos de dichos cambios, de acuerdo cestablecido en las nioninas. 
TABLA 6 (CONTINUACIÓN)

Principios de contabilidad

\begin{tabular}{l}
\hline Colombia \\
\hline No compensación: no se reconocen ni se \\
presentan partidas netas como efecto de \\
compensar activos y pasivos del estado de \\
situación financiera, o ingresos, gastos y \\
costos que integran el estado de resultados, \\
salvo en aquellos casos en que, de forma \\
excepcional, así se regule. \\
Periodo contable: corresponde al tiempo \\
máximo en que la entidad mide los \\
resultados de sus hechos económicos y el \\
patrimonio bajo su control, efectuando las \\
operaciones contables de ajustes y cierre. \\
El periodo contable es el lapso transcurrido \\
entre el $1^{\circ}$ de enero y el 31 de diciembre. \\
No obstante, se pueden solicitar estados \\
financieros intermedios e informes y \\
reportes contables para propósitos \\
especiales, de acuerdo con las necesidades \\
o requerimientos de las autoridades \\
competentes, sin que esto signifique, \\
necesariamente, la ejecución de un cierre.
\end{tabular}

Fuente: elaboración propia. Resolución 533 del 8 de octubre de 2015 y CGR 016 del 16 de febrero de 2015.

De acuerdo con la tabla anterior, los principios contables chilenos están resumidos en tres reglas básicas que son: gestión continuada, devengo e imputación presupuestaria; en tanto que los principios colombianos contemplan siete principios contables de obligatorio cumplimiento así: entidad en marcha, devengo, esencia sobre forma, asociación, uniformidad, no compensación y período contable.

En Colombia, el anterior Plan General de Contabilidad Pública (PGCP), expedido mediante la Resolución 355 de 2007, contempló además los principios de registro, medición, prudencia y revelación, los cuales fueron eliminados en el proceso de convergencia a las Nicsp (CGN, 2007).

Los principios de contabilidad constituyen un soporte fundamental en el desarrollo del proceso contable, desde la etapa de reconocimiento hasta la revelación de la información financiera, dado que lo orienta y delimita para cumplir con los objetivos propuestos en el marco normativo contable, por tal razón se deben incorporar en una política contable, con el fin de que puedan ser evaluados periódicamente y garantizar que la entidad continua funcionando en forma normal y que su información corresponde a la realidad de los hechos económicos que allí se generan.

\section{Elementos de los estados financieros}

Los estados financieros representan los efectos de las transacciones y de otros sucesos agrupados en categorías que comparten características económicas comunes y que corresponden a los estados financieros, es decir, 
que esos elementos están relacionados directamente con la situación financiera de los activos, los pasivos y el patrimonio, y con el rendimiento financiero de los ingresos, costos y gastos.

TABLA 7

Elementos de los estados financieros

\begin{tabular}{|c|c|}
\hline Colombia & Chile \\
\hline $\begin{array}{l}\text { Resolución } 533 \text { del } 8 \text { de octubre de } 2015 \text {. } \\
\text { 6.1. Definición de los elementos de los } \\
\text { estados financieros. }\end{array}$ & $\begin{array}{l}\text { Resolución CGR } 016 \text { del } 16 \text { de febrero de } \\
2015 \\
\text { Capítulo 1. Marco conceptual }\end{array}$ \\
\hline
\end{tabular}

Activos: son recursos controlados por la entidad que resultan de un evento pasado y de los cuales se espera obtener un potencial de servicio o generar beneficios económicos futuros.

Pasivos: es una obligación presente producto de sucesos pasados para cuya cancelación, una vez vencida, la entidad espera desprenderse de recursos que incorporan beneficios económicos o un potencial de servicio.

Patrimonio: comprende el valor de los recursos públicos (representados en bienes y derechos), deducidas las obligaciones, que tiene la entidad de gobierno para cumplir las funciones de cometido estatal.

Ingresos: son los incrementos en los benefícios económicos o en el potencial de servicio producidos a lo largo del periodo contable (bien en forma de entradas o incrementos de valor de los activos, o bien como salidas o decrementos de los pasivos) que dan como resultado aumentos del patrimonio y no están relacionados con los aportes para la creación de la entidad.
Activos: recursos en bienes y derechos controlados por la entidad como resultado de los actos y contratos realizados en el transcurso de su gestión pasada, de los cuales se espera obtener en el futuro beneficios económicos o un potencial de servicio.

Pasivos: son las obligaciones presentes de la entidad que surgen de hechos pasados, cuya solución o pago se espera que represente un flujo de salida de recursos, que incorporen beneficios económicos o un potencial de servicio.

Patrimonio: es la parte residual de los activos de la entidad, una vez deducido todos sus pasivos.

Ingresos patrimoniales: son los incrementos brutos de beneficios económicos o potencial de servicio del periodo que implican aumentos indirectos del patrimonio.

Gastos patrimoniales: son las reducciones brutas de beneficios económicos o potencial de servicio del periodo que implican disminuciones indirectas del patrimonio. 
TABLA 7 (CONTINUACIÓN)

Elementos de los estados financieros

Colombia
Gastos: son los decrementos en los
beneficios económicos o en el potencial de
servicio producidos a lo largo del periodo
contable (bien en forma de salidas o
disminuciones del valor de los activos, o bien
por la generación o aumento de los pasivos),
que dan como resultado decrementos en el
patrimonio y no están asociados con la
adquisición o producción de bienes y la
prestación de servicios, vendidos, ni con la
distribución de excedentes.

Costos: son los decrementos en los beneficios económicos o en el potencial de servicio producidos a lo largo del periodo contable, los cuales están asociados con la adquisición o producción de bienes y la prestación de servicios, vendidos (con independencia de que en el intercambio se recuperen o no los costos) y que dan como resultado decrementos en el patrimonio.

\section{Chile}

Ingresos presupuestarios: corresponden a los flujos de recursos financieros destinados a financiar los gastos presupuestarios del ejercicio. Se pueden originar, entre otros, en ingresos por impuestos y otros tributos, imposiciones previsionales, aporte fiscal, otras transferencias, ingresos financieros, reembolso de préstamos, enajenación de activos, endeudamiento y otros ingresos patrimoniales.

Gastos presupuestarios: representan los flujos financieros correspondientes a la aplicación de los recursos de la entidad que han sido autorizados como gastos en el presupuesto. Tienen su origen en desembolsos para el funcionamiento de la entidad, adquisición de activos financieros y no financieros, otras inversiones de capital, otorgamiento de préstamos, transferencias y la disminución de pasivos financieros.

Fuente: elaboración propia. Resolución 533 del 8 de octubre de 2015 y CGR 016 del 16 de febrero de 2015.

En el campo del catálogo general de cuentas, Colombia y Chile definen los elementos de los estados financieros con base en el marco conceptual de la IFAC; no obstante, Chile denomina a las cuentas de resultado como ingresos patrimoniales y gastos patrimoniales, toda vez que algún cambio se refleja en el patrimonio de la entidad pública.

En el campo presupuestal, el gobierno de Chile incorpora en su catálogo las cuentas de ingresos presupuestarios y gastos presupuestarios, con el fin de articular las operaciones económicas con la ejecución presupuestal de ingresos y gastos que se ejecutan paralelamente en el cumplimiento de la misión de la institución pública. Para el caso de Colombia, esta articulación se puede evidenciar directamente en el software contable que articula los módulos presupuestales, la facturación, la cartera y la tesorería, para generar información en línea y en tiempo real para efectos de presentación de la información.

Los catálogos generales de cuentas se constituyen en instrumento de control de la información y un apoyo a las herramientas tecnológicas que permiten identificar las diferentes operaciones financieras, económicas y sociales de una entidad pública para la adecuada presentación de los estados financieros; por tal razón se hace necesario identificar a través de sus usuarios la necesidad de actualizarlos mediante la incorporación o eliminación de cuentas y reflejar así todas las operaciones que se generan durante el desarrollo del cometido estatal. 


\section{Criterios de valoración para elementos de los estados financieros}

TABLA 8

Criterios de valoración para elementos de los estados financieros

Colombia
Resolución 533 del 8 de octubre de 2015.
6.3 . Medición de los activos
Medición de los activos costo: el costo
corresponde al importe de efectivo o
equivalentes al efectivo pagados, o bien al
valor de la contraprestación entregada, para
adquirir un activo en el momento de su
adquisición o desarrollo. El costo es un valor
de entrada observable y especifico para la
entidad.

Según este criterio, los activos se reconocen inicialmente por el efectivo y otros cargos pagados o por pagar para la adquisición, formación y colocación de los bienes en condiciones de utilización o enajenación.

Costo reexpresado: corresponde a la actualización del costo de los activos con el fín de reconocer cambios de valor ocasionados por la exposición a fenómenos económicos exógenos. Para tal efecto, se emplea la tasa de cambio de la moneda extranjera, los pactos de ajuste, la unidad de valor real o cualquier otra modalidad admitida formalmente.
Chile

Resolución CGR 016 del 16 de febrero de 2015.

\section{Capítulo I. Marco conceptual}

\section{Criterios de valorización de los activos}

Precio de adquisición: es la suma, en efectivo $\mathrm{u}$ otros activos, pagada o que la entidad se ha comprometido a pagar, así como cualquier costo directamente relacionado con la compra o puesta en condiciones de servicio del activo para el uso al que está destinado.

Costo de producción: comprende el precio de adquisición de las materias primas y otros materiales consumibles, el de los factores de producción directamente imputables al mismo y una porción razonable de los indirectamente relacionados con tal activo, correspondientes, en todo caso, con el período de producción, elaboración o construcción.

Valor razonable: es la cantidad por la que puede ser intercambiado un activo o liquidado un pasivo entre un comprador y un vendedor interesados y debidamente informados, en condiciones de independencia mutua. 
TABLA 8 (CONTINUACIÓN)

Criterios de valoración para elementos de los estados financieros

\section{Colombia}

Costo amortizado: corresponde al valor del activo inicialmente reconocido, más el rendimiento efectivo, menos los pagos de capital e intereses, menos cualquier disminución por deterioro del valor. El costo amortizado es un valor de entrada observable y especifico para la entidad.

Costo de reposición: corresponde a la contraprestación más baja requerida para reemplazar el potencial de servicio restante de un activo o los beneficios económicos incorporados a este. El costo de reposición es un valor de entrada observable y especifico para la entidad.

Valor de mercado: es el valor por el cual un activo puede ser intercambiado entre partes interesadas y debidamente informadas, en una transacción realizada en condiciones de independencia mutua. Cuando el valor se obtiene en un mercado abierto, activo y ordenado, el valor de mercado puede ser un valor de entrada o de salida observable y un valor no específico para la entidad.

\section{Chile}

Este valor no tendrá en cuenta los costos de transacción en los que se pueda incurrir si se enajena el elemento patrimonial. La definición de valor razonable incorpora el principio de gestión contimuada $\mathrm{y}$, por lo tanto, no es la cantidad que se recibiría en una transacción forzada.

Valor realizable neto: el valor realizable neto de un activo es la cantidad que se puede obtener por su venta en el mercado, de manera natural o no forzada, menos los costos estimados necesarios para llevar a cabo la venta, intercambio o distribución y, en el caso de los productos en proceso, los costos estimados para terminar su producción o construcción.

Costo corriente de reposición: es aquel en el que la entidad incurriría al adquirir el activo en la fecha de presentación. 
TABLA 8 (CONTINUACIÓN)

Criterios de valoración para elementos de los estados financieros

\begin{tabular}{l}
\hline Colombia \\
Valor neto de realización: es el valor que la \\
entidad puede obtener por la venta de los \\
activos, menos los costos estimados para \\
terminar su producción y los necesarios para \\
llevar a cabo su venta. \\
El valor neto de realización, a diferencia del \\
valor de mercado, no requiere un mercado \\
abierto, activo y ordenado o la estimación de \\
un precio en tal mercado. El valor neto de \\
realización es un valor de salida observable y \\
específico para la entidad.
\end{tabular}

Valor en uso: equivale al valor presente de los beneficios económicos que se espera genere el activo, incluido el flujo que recibiría la entidad por su disposición al final de la vida útil. El valor en uso es un valor de salida no observable y específico para la entidad.

\section{Medición de los pasivos}

Costo: el costo de un pasivo es la contraprestación recibida a cambio de la obligación asumida, esto es, el efectivo o equivalente al efectivo pagado, o el valor de la contraprestación recibida en el momento de incurrir en el pasivo. El costo es un valor de entrada observable $y$ especifico para una entidad.

\section{Chile}

Valor de uso: el valor de uso de aquellos activos que incorporan beneficios económicos futuros se define como el valor actual de los flujos de efectivo esperados a través de su utilización en el curso normal de la actividad de la entidad y, en su caso, de su enajenación u otra forma de disposición.

Costo de venta: son los gastos directamente atribuibles a la venta de un activo, en los que la entidad no habría incurrido de no haber tomado la decisión de vender, excluidos los gastos financieros. Se incluyen los gastos legales necesarios para transferir la propiedad del activo y las comisiones de venta.

Monto recuperable: el monto recuperable de un activo es el que resulte mayor de entre su valor razonable, menos los costos de venta y su valor de uso.

Valor actual de un activo o pasivo: es el monto de los flujos de efectivo a recibir o pagar, respectivamente, en el curso normal de la actividad de la entidad, actualizados a una tasa de descuento adecuada. 
TABLA 8 (CONTINUACIÓN)

Criterios de valoración para elementos de los estados financieros

\section{Colombia}

Costo reexpresado: corresponde a la actualización del costo de los pasivos con el fin de reconocer cambios de valor ocasionados por la exposición a fenómenos económicos exógenos. Para tal efecto se emplea la tasa de cambio de la moneda extranjera, los pactos de ajuste, la unidad de valor real o cualquier otra modalidad admitida formalmente.

Costo amortizado: corresponde al valor del pasivo inicialmente reconocido, más el costo efectivo, menos los pagos de capital e intereses. El costo amortizado es un valor de entrada observable y específico para la entidad.

Costo de cumplimiento: representa la mejor estimación de los costos en que la entidad incurriría para cumplir las obligaciones representadas por el pasivo. Es un valor de salida no observable y específico para una entidad.

Valor de mercado: el valor de mercado de un pasivo es el valor por el cual la obligación puede ser liquidada o transferida entre partes interesadas y debidamente informadas, en una transacción realizada en condiciones de independencia mutua. Cuando el valor se obtiene en un mercado abierto, activo y ordenado, el valor de mercado puede ser un valor de entrada o de salida observable y un valor no específico para la entidad.

\section{Chile}

Costo amortizado de un activo o pasivo

financiero: es el monto por el que inicialmente fue valorizado, menos los reembolsos del principal que se hubieran cobrado, más la parte imputada en los resultados del ejercicio, mediante el método de la tasa de interés efectiva, sobre la diferencia entre el monto inicial y el valor de reembolso y menos cualquier reducción de valor por deterioro.

Costos de transacción atribuibles a un activo o pasivo financiero: son los gastos directamente atribuibles a la compra o venta de un activo financiero, o a la emisión o adquisición de un pasivo financiero, en los que no se habría incurrido si la entidad no hubiera realizado la transacción.

Entre ellos se incluyen los honorarios y comisiones pagados a intermediarios, tales como las de corretaje, los gastos notariales, impuestos y otros. Se excluyen las primas o descuentos obtenidos en la compra o emisión y los gastos incurridos por estudios y análisis previos.

Valor contable o valor en libros: es el monto por el que un activo o un pasivo se encuentra registrado en el balance, menos, en el caso de los activos, la depreciación o amortización acumulada y cualquier deterioro reconocido.

Valor residual de un activo: es la cantidad que la entidad podría obtener actualmente por su venta u otra forma de disposición, menos los costos estimados para realizar esta, si el activo hubiese alcanzado ya la antigüiedad y las demás condiciones esperadas al término de su vida útil. 
TABLA 8 (CONTINUACIÓN)

Criterios de valoración para elementos de los estados financieros

\begin{tabular}{ll}
\hline Colombia & Chile \\
\hline Criterios de valorización de los pasivos \\
Costo de un pasivo: es el valor de la \\
contrapartida recibida a cambio de incurrir en \\
la deuda. \\
Valor razonable: es la cantidad por la que \\
puede ser intercambiado un activo o liquidado \\
un pasivo entre un comprador y un vendedor \\
interesados y debidamente informados, en \\
condiciones de independencia mutua. \\
Este valor no tendrá en cuenta los costos de \\
transacción en los que se pueda incurrir si se \\
enajena el elemento patrimonial. La definición \\
de valor razonable incorpora el principio de \\
gestión continuada y, por lo tanto, no es la \\
cantidad que se recibiría en una transacción \\
forzada.
\end{tabular}

Valor actual de un activo o pasivo: es el monto de los flujos de efectivo a recibir o pagar, respectivamente, en el curso normal de la actividad de la entidad, actualizados a una tasa de descuento adecuada.

Costo amortizado de un activo o pasivo financiero: es el monto por el que inicialmente fue valorizado, menos los reembolsos del principal que se hubieran cobrado, más la parte imputada en los resultados del ejercicio, mediante el método de la tasa de interés efectiva, sobre la diferencia entre el monto inicial y el valor de reembolso y menos cualquier reducción de valor por deterioro. 
TABLA 8 (CONTINUACIÓN)

Criterios de valoración para elementos de los estados financieros

\begin{tabular}{ll}
\hline Colombia & Chile \\
\hline & Costos de transacción atribuibles a un \\
activo o pasivo financiero: son los gastos \\
directamente atribuibles a la compra o venta de \\
un activo financiero o a la emisión o \\
adquisición de un pasivo financiero, en los que \\
no se habría incurrido si la entidad no hubiera \\
realizado la transacción. \\
Entre ellos se incluyen los honorarios y \\
comisiones pagadas a intermediarios, tales \\
como las de corretaje, los gastos notariales, \\
impuestos y otros. Se excluyen las primas o \\
descuentos obtenidos en la compra o emisión \\
y los gastos incurridos por estudios y análisis \\
previos. \\
Valor contable o valor en libros: es el monto \\
por el que un activo o un pasivo se encuentra \\
registrado en el balance, menos, en el caso de \\
los activos, la depreciación o amortización \\
acumulada y cualquier deterioro reconocido.
\end{tabular}

Fuente: elaboración propia. Resolución 533 del 8 de octubre 8 de 2015 y CGR 016 del 16 de febrero de 2015.

La valoración o medición es el proceso por el que se asigna un valor monetario a cada elemento de los estados financieros, de acuerdo con lo dispuesto en las normas específicas relativas a cada uno de ellos. Ahora bien, entendiendo que un solo criterio no satisface íntegramente todos los objetivos posibles ni permite alcanzar los niveles máximos de utilidad en relación con la toma de decisiones, se han considerado diferentes criterios de valorización, tal como se detallaron en los párrafos anteriores.

En el caso colombiano, los criterios de medición se pueden clasificar dependiendo si son valores de entrada o salida, si son observables o no en un mercado abierto, y si son mediciones específicas o no para una entidad.

$\mathrm{Al}$ momento de construir un manual de políticas contables es necesario verificar la asignación del criterio de medición para cada bien del ente público, mediante la aplicación de la característica de materialidad, la representación fiel y su relación costo-beneficio, porque puede generar un desgaste administrativo para su control interno y no tener ningún valor para el usuario, dado que no afecta la toma de decisiones de la entidad pública. 


\section{Comparativo de definición de activos generadores y no generadores de efectivo}

TABLA 9

Comparativo de definición de activos generadores y no generadores de efectivo

Colombia
Resolución 533 del 8 de octubre de 2015.
Activo generador de efectivo:
Cuando un activo se gestiona
fundamentalmente para generar,
directamente o a través de la unidada la que
pertenece, flujos de caja y obtener un
rendimiento comercial que refleje el riesgo
que implica la posesión del mismo, este
activo se considera generador de efectivo

Activo no generador de efectivo:

Chile

Resolución CGR 016 del 16 de febrero de

2015.

Cuando una entidad gestiona un activo con el fin de prestar un servicio y no con el propósito de obtener flujos de caja ni un rendimiento comercial que refleje el riesgo que implica su posesión.

Activo generador de efectivo: (Cashgenerating assets) son aquellos que se mantienen para obtener un rendimiento comercial.

Activos no generadores de efectivo: (Noncash-generating assets) son aquellos activos distintos a los activos generadores de efectivo.

Fuente: elaboración propia. Resolución 533 del 8 de octubre de 2015 y CGR 016 del 16 de febrero de 2015.

Los marcos conceptuales de contabilidad pública de los dos países contemplan las mismas definiciones en cuanto a activo y deterioro de bienes que generan beneficios económicos o contribuyen con un potencial de servicios, dado que la fuente fueron las Nicsp.

$\mathrm{Al}$ momento de clasificar estos bienes es necesario identificar si es para utilizarlos en la generación de beneficios económicos en condiciones de mercado o para la prestación de servicios en forma gratuita o a precio de no mercado, lo cual permitirá generar informes complementarios que pueden contribuir a la toma de decisiones y a un buen uso de los recursos públicos. Son ejemplos de activos generadores de efectivo las propiedades, plantas y equipos, propiedades de inversión, intangibles que son utilizados en la producción de bienes y servidos en condiciones de mercado y no generadores de efectivo, como los bienes de uso público e históricos y culturales. 


\section{Comparativo del deterioro del valor de los activos no generadores de efectivo}

TABLA 10

Comparativo del deterioro del valor de los activos no generadores de efectivo

Colombia
Resolución 533 del 8 de octubre de 2015.
$\begin{aligned} & \text { Deterioro del valor de los activos no } \\ & \text { generadores de efectivo }\end{aligned}$

Definición: el deterioro del valor de un activo no generador de efectivo es la pérdida en su potencial de servicio, adicional al reconocimiento sistemático realizado a través de la depreciación o amortización.

Los activos no generadores de efectivo son aquellos que la entidad mantiene con el propósito fundamental de suministrar bienes o prestar servicios en forma gratuita o a precios de no mercado, es decir, la entidad no pretende, a través del uso del activo, generar rendimientos en condiciones de mercado.

Periodicidad de la comprobación del deterioro del valor: como mínimo, al final del periodo contable, la entidad evaluará si existen indicios de deterioro del valor de sus activos no generadores de efectivo. Si existe algún indicio, la entidad estimará el valor de servicio recuperable del activo para comprobar si efectivamente se encuentra deteriorado; en caso contrario, la entidad no estará obligada a realizar una estimación formal del valor del servicio recuperable.

\section{Medición del valor del servicio} recuperable: para comprobar el deterioro del valor del activo, la entidad estimará el valor del servicio recuperable, el cual corresponde al mayor valor entre el valor de mercado, menos los costos de disposición y el costo de reposición.
Chile

Resolución CGR 016 del 16 de febrero de 2015.

Capítulo II. Norma especifica el deterioro de activos generadores y no generadores de efectivo

Definición: deterioro del valor es una pérdida en el potencial de servicio futuro de un activo, adicional y diferente del reconocimiento anual de la pérdida por depreciación, que se efectúa de manera excepcional.

El deterioro se deberá reconocer cuando el valor libro del activo exceda a su monto recuperable, siempre que dicha diferencia sea significativa. Si este valor es mayor a quince UTM, se deberá pedir autorización a la Contraloría General para efectuar un ajuste por deterioro o una reversión de este.

Valorización: el monto del deterioro corresponde a la diferencia entre el valor libro y el monto recuperable del activo.

Monto recuperable: el monto recuperable de un activo es igual al mayor entre su valor razonable, menos los costos necesarios para la venta y su valor en uso.

El valor en uso se determina de acuerdo con el hecho de si el activo es generador o no generador de efectivo.

Se consideran como activos no generadores de efectivo aquellos bienes que no son destinados a la producción de bienes o servicios para la venta, cuando los beneficios recibidos resultan en un aumento indirecto del patrimonio. 
TABLA 10 (CONTINUACIÓN)

Comparativo del deterioro del valor de los activos no generadores de efectivo

\section{Colombia}

Valor de mercado menos los costos de disposición: el valor de mercado se determinará conforme a lo definido en el Marco Conceptual para esta base de medición. Los costos de disposición, diferentes de aquellos reconocidos como pasivos, se deducirán del valor de mercado. Estos costos incluyen entre otros, costos de carácter legal, timbres y otros impuestos de la transacción similares, los costos de desmontaje o desplazamiento del activo, así como todos los demás costos incrementales para dejar el activo en condiciones para la venta. No son costos incrementales directamente relacionados y atribuibles a la disposición del activo, los beneficios por terminación del vínculo laboral o contractual y otros costos asociados con la reducción del tamaño o la reorganización de un negocio que implique la venta o disposición, por otra vía, de un activo.

Costo de reposición: el costo de reposición para un activo no generador de efectivo está determinado por el costo en el que la entidad incurriría en una fecha determinada para reponer la capacidad operativa del activo existente. La entidad podrá emplear los enfoques que se exponen en los siguientes numerales a efecto de estimar el costo de reposición.

Costo de reposición a nuevo ajustado por depreciación: la entidad podrá estimar el costo de reposición teniendo en cuenta los recursos que tendría que sacrificar para reponer el potencial de servicio bruto de un activo (bien sea a través de la reproducción del activo o bien de la sustitución por uno que tenga el mismo potencial de servicio); este costo se ajustará por la depreciación de acuerdo con la vida útil consumida del activo que es objeto de cálculo de deterioro.

\section{Chile}

$\mathrm{Si}$ el valor en uso del activo no excede de forma significativa a su valor razonable, menos los costos necesarios para la venta, puede tomarse este como valor recuperable del mismo.

Valor en uso de activos no generadores de efectivo: se define como el valor presente del potencial de servicios restante del activo. Este se determina usando cualquiera de los siguientes enfoques:

a) Enfoque del costo de reposición depreciado: este costo se mide como el menor entre el costo de reproducción (réplica) o el de reposición del activo, menos la depreciación acumulada calculada sobre la base de tal costo, para reflejar la parte ya consumida o potencial del servicio agotada del activo. El costo de reproducción y el costo de reposición se calculan respecto de la capacidad óptima que debería tener el activo para su uso actual;

b) Enfoque del costo de rehabilitación: es el costo de devolver el potencial de servicio de un activo al nivel anterior al deterioro. El valor en uso del activo se determina restando el costo estimado de rehabilitación del activo a su costo actual de reposición depreciado anterior al deterioro;

c) Enfoque de las unidades de servicio: el valor corriente del potencial de servicio restante de un activo se determina reduciendo el costo de reposición depreciado del activo anterior al deterioro, para ajustarlo al número reducido de unidades de servicio esperadas del activo en su estado de deterioro.

La elección del enfoque más adecuado para determinar el valor en uso depende de los datos disponibles y de la naturaleza del deterioro. 
TABLA 10 (CONTINUACIÓN)

Comparativo del deterioro del valor de los activos no generadores de efectivo

\begin{tabular}{l}
\hline Colombia \\
Costo de reposición a nuevo ajustado por \\
depreciación y rehabilitación: la entidad \\
podrá estimar el costo de reposición teniendo \\
en cuenta los recursos que tendría que \\
sacrificar para reponer el potencial de \\
servicio bruto de un activo (bien sea a través \\
de la reproducción del activo o de la \\
sustitución de este por uno que tenga el \\
mismo potencial de servicio); este costo se \\
ajustará por la depreciación de acuerdo con \\
la vida útil ya consumida del activo que es \\
objeto de cálculo de deterioro y por el costo \\
en que incurriría para devolver el potencial \\
de servicio que se perdió por el daño físico \\
del activo. \\
Este enfoque se privilegia cuando el \\
deterioro del valor se origina por un daño \\
físico del activo.
\end{tabular}

Fuente: elaboración propia. Resolución 533 del 8 de octubre de 2015 y CGR 016 del 16 de febrero de 2015.

Los dos países retoman los conceptos de las normas internacionales de contabilidad para el sector público, salvo que Colombia, en su marco normativo para entidades de gobierno, no contempló el enfoque de las unidades de servicio para el cálculo del deterioro.

Desde el punto de vista administrativo y para efectos de mayor control de los activos, es importante elaborar inventarios físicos semestrales o anuales que permitan identificar el estado del bien, al funcionario responsable y el uso del mismo, para revelar información más ajustada a la situación del bien en un momento determinado. Al momento de construir la política contable para el deterioro, debe considerarse la característica de materialidad, el periodo de evaluación del deterioro, que podría ser como mínimo una vez al año, para que se refleje en el estado de la situación financiera de la entidad, así como factores internos o externos y establecer documentos soportes que reflejen estos cambios, como videos, declaraciones de empleados, planos y fotografías, entre otros.

Los siguientes ejemplos reflejan los diferentes enfoques requeridos para estimar el costo de reposición para la medición del servicio recuperable de los activos no generadores de efectivo en una entidad de gobierno.

\section{Caso 1. Costo de reposición a nuevo ajustado por depreciación de un equipo de cómputo}

La alcaldía de "El Futuro" adquirió el 2 de enero de 2015 un equipo de cómputo central por valor de \$ 10 000 000; el municipio estimó una vida útil de siete años y una capacidad de utilización del $100 \%$. El 31 de diciembre de 2018 bajó su capacidad al 10 \%, porque las áreas o dependencias pasaron a ejecutarse en 
servidores u ordenadores. Un ordenador con la misma capacidad o equivalente a la que realiza el computador central, en la actualidad se puede adquirir en el mercado por \$ 500000 .

Evalúe el deterioro:

Una disminución significativa en el nivel de uso es un indicio de deterioro, y la pérdida se determina de la siguiente forma:

1. Costo de adquisición en enero de 2015: \$10000 000 .

Depreciación acumulada a diciembre 31 de 2018 (cuatro años): $\$ 10000000 * 4 / 7=\$ 5714286$.

2. . Saldo o importe en libros a diciembre de 2018: \$1 $000000(-) \$ 5714286=\$ 4285714$

3. Costo de reposición de un activo similar $\$ 500000$.

4. Depreciación acumulada al 31 de diciembre de 2018 (cuatro años): $\$ 500000 * 4 / 7=\$ 285714$

5. Saldo o importe del costo de reposición, menos la depreciación acumulada: \$ $500000(-) \$ 285$ $714=\$ 214286$.

Pérdida por deterioro $(2-5): \$ 4285714(-) \$ 214286=\$ 4071428$.

\section{Caso 2. Costo de reposición a un nuevo activo ajustado por depreciación de una escuela que cambió de fin educativo a bodega}

El municipio de Rionegro (Antioquia), el 2 de enero de 2015 construyó una escuela para educación primaria a unos costos de \$ 10000 000; la vida útil estimada fue 50 años. En diciembre de 2020 es cerrada la escuela debido a la disminución de los alumnos matriculados, por la quiebra de la empresa Textiles XYZ S.A., que generaba la mayor fuente de empleo para los padres de los alumnos; el municipio les cambió el uso a las instalaciones educativas por el de una bodega para almacenar productos agrícolas. El costo actual de reposición para una bodega con la misma capacidad es de \$4200 000. Evalúe el deterioro del inmueble.

1. Costo histórico el 2 de enero de 2015: \$ 10000000.

2. Depreciación acumulada a diciembre de 2020 (seis años): $\$ 10000000^{*} 6 / 50=\$ 1200000$.

3. Valor en libros (costo histórico [-] depreciación acumulada): \$10000 000 (-) \$1200000=\$ 8800000 .

4. Costo de reposición de una bodega de igual capacidad: $\$ 4200000$.

5. Depreciación acumulada de la bodega (seis años): $\$ 4200000 * 6 / 50=\$ 504000$.

6. Importe de servicio recuperable $(4-5)=\$ 3696000$.

Pérdida por deterioro (3-6)

$\$ 8800000-\$ 3696000=\$ 5104000$

\section{Caso 3. Costo de reposición a nuevo del activo ajustado por depreciación y rehabilitación}

El colegio Marco Fidel Suárez, ubicado en el municipio de Bello (Antioquia), compró un vehículo para el transporte de los profesores y alumnos, el 2 de enero de 2015, por valor de $\$ 200000$ 000; la vida útil estimada del vehículo fue de 10 años. Luego, en el año 2019, el vehículo sufre un accidente y fue necesario hacer una reparación por valor de $\$ 40000000$, para ponerlo nuevamente en funcionamiento; la reparación no afectó la vida útil del bien. El valor de un vehículo nuevo para prestar un servicio similar en el año 2019 es de \$250 000000 . Evalúe el deterioro del activo.

Solución: 
1. Costo de adquisición del vehículo (2015): \$200000 000 .

2. Depreciación acumulada (2020) en cinco años: $\$ 200000000 * 5 / 10=\$ 100000000$.

3. Valor en libros en el 2020: $\$ 200000000(-) \$ 100000000=\$ 100000000$

Costo de reposición $\$ 250000000$.

Depreciación acumulada (cinco años): $\$ 250000000^{*} 5 / 10=\$ 125000000$.

4. Costo de reposición y depreciado-sin reparación: \$ 125000000.

Menos costo de rehabilitación (\$40000 000).

5. Importe del servicio recuperable: $\$ 85000000$.

Pérdida por deterioro (3-5) \$15000 000 .

\section{Comparativo del catálogo general de cuentas}

TABLA 11

Comparativo del catálogo general de cuentas

\begin{tabular}{ll}
\hline Colombia & Chile \\
\hline Resolución 620 de diciembre de 2015. & Resolución CGR 016 del 16 de febrero de \\
Catálogo general de cuentas. & 2015.
\end{tabular}

\section{Capítulo 1. Estructura}

La estructura del Catálogo General de Cuentas está conformada por cuatro niveles de clasificación con seis dígitos que conforman el Código contable de la siguiente manera:

\begin{tabular}{|l|l|l|l|}
\hline Clase & Grupo & Cuenta & Subcuenta \\
\hline $\mathrm{x}$ & $\mathrm{xx}$ & $\mathrm{Xxxx}$ & $\mathrm{Xxxxxx}$ \\
\hline
\end{tabular}

El primer dígito del código contable corresponde a la clase, el segundo al grupo, el tercero y cuarto dígitos corresponden a la cuenta y el quinto y sexto a la subcuenta.

\section{Capítulo III: plan de cuentas para el sector público}

La codificación para identificar los distintos niveles de agrupación que comprende el plan de cuentas es numérica.

Nivel de Agrupación Rango:

Título: $5 / 9$

Grupo: 53/99

Subgrupo: $531 / 999$

Cuenta Nivel 1: 53101/99999

Cuenta Nivel 2: 5310101/9999999

Cuenta Nivel 3: 531010101/999999999 
TABLA 11 (CONTINUACIÓN)

Comparativo del catálogo general de cuentas

\section{Colombia}

La definición de las clases, grupos, cuentas y subcuentas está reservada para la Contaduria General de la Nación. A partir de alli, las entidades podrán habilitar, discrecionalmente, niveles auxiliares en función de sus necesidades especificas, excepto para los casos en los cuales se regule la estructura de este nivel.

1. Clases: El Catálogo General de Cuentas está integrado por las nueve clases siguientes:

1. Activos

2. Pasivos

3. Patrimonio

4. Ingresos

5. Gastos

6. Costos de ventas

7. Costos de transformación

8. Cuentas de orden deudoras

9. Cuentas de orden acreedoras.

Las clases 1 a 3 representan la situación financiera; las clases 4 a 6 contienen las cuentas de resultados financieros del periodo; la clase 7 representa la acumulación de los costos asociados a la transformación de bienes y prestación de servicios durante el periodo contable; y las clases 8 y 9 representan contingencias y revelan información para efectos de control.
Chile

La identificación del código a nivel de título es la siguiente:

Título denominación

1. Activo

2. Pasivo

3. Patrimonio

4. Ingresos patrimoniales

5 . Gastos patrimoniales

9. Cuentas de responsabilidades o derechos eventuales.

A continuación se detallan a nivel de grupo las cuentas de la situación financiera y resultados:

\section{Grupos}

\section{Clase 1. Activos}

Grupo 11. Recursos disponibles

Grupo 12. Bienes financieros

Grupo 13. Bienes de consumo y existencias

Grupo 14. Bienes de uso

Grupo 15. Otros activos

Grupo 16. Costos de proyectos y programas. 
TABLA 11 (CONTINUACIÓN)

Comparativo del catálogo general de cuentas

Colombia
- Grupos: Las clases están compuestas por
grupos asi:

\section{Clase 1. Activos}

\section{Grupos:}

11. Efectivo y equivalentes al efectivo

12. Inversiones e instrumentos derivados

13. Cuentas por cobrar

14. Préstamos por cobrar

15. Inventarios

16. Propiedades, planta y equipo

17. Bienes de uso público e históricos y culturales

18. Recursos naturales no renovables

19. Otros activos.

\section{Clase 2. Pasivos}

Grupos:

22. Emisión y colocación de títulos de deuda

23. Préstamos por pagar

24. Cuentas por pagar

25. Beneficios a los empleados

26. Operaciones con instrumentos derivados

27. Provisiones

29. Otros pasivos.

\section{Chile}

Clase 2. Pasivos

Grupo 21. Deuda corriente

Grupo 22. Otras deudas

Grupo 23. Deuda pública.

Clase 3. Patrimonio

Grupo 31. Patrimonio del Estado

\section{Clase 4. Ingresos}

Grupo 41. Ingresos tributarios

Grupo 42. Imposiciones previsionales

Grupo 43. Ingresos operacionales

Grupo 44. Transferencias recibidas

Grupo 45. Venta de activos

Grupo 46. Otros ingresos patrimoniales.

\section{Clase 5. Gastos}

Grupo 51. Traspasos al fisco

Grupo 52. Prestaciones de seguridad social

Grupo 53. Gastos operacionales

Grupo 54. Transferencias otorgadas

Grupo 55. Costo de venta

Grupo 56. Otros gastos patrimoniales

Grupo 57. Gastos en inversión pública. 
TABLA 11 (CONTINUACIÓN)

Comparativo del catálogo general de cuentas

Colombia

\section{Clase 3. Patrimonio}

Grupos:

31. Patrimonio de las entidades del gobierno.

\section{Clase 4. Ingresos}

Grupos:

41. Ingresos fiscales

42. Venta de bienes

43. Venta de servicios

44. Transferencias y subvenciones

47. Operaciones interinstitucionales

48. Otros ingresos.

\section{Clase 5. Gastos}

Grupos:

51. De administración y operación

52. De ventas

53. Deterioro, depreciaciones, amortizaciones y provisiones.

54. Transferencias y subvenciones

55. Gasto público social

56. De actividades y/o servicios especializados.

57. Operaciones interinstitucionales

58. Otros gastos

59. Cierre de ingresos, gastos y costos.

\section{Chile}

Clase 9. Cuentas de responsabilidades contingentes

9. Cuentas de responsabilidades o derechos eventuales 
TABLA 11 (CONTINUACIÓN)

Comparativo del catálogo general de cuentas

Colombia Chile

\section{Clase 6. Costos de ventas}

Grupos:

62. Costo de ventas de bienes

63. Costo de ventas de servicios.

\section{Clase 7. Costos de transformación}

Grupos:

71. Bienes

72. Servicios educativos

73. Servicios de salud

74. Servicios de transporte

75. Servicios públicos

76. Servicios hoteleros y de promoción turística.

79. Otros servicios.

\section{Clase 8. Cuentas de orden deudoras}

Grupos:

81. Activos contingentes

82. Deudoras fiscales

83. Deudoras de control

89. Deudoras por contra (cr).

\section{Clase 9. Cuentas de orden acreedoras}

Grupos:

91. Pasivos contingentes

92. Acreedoras fiscales

93. Acreedoras de control

99. Acreedoras por contra (db).

Fuente: elaboración propia. Resolución 620 de diciembre de 2015 y CGR 016 del 16 de febrero de 2015.

El plan de cuentas para el sector público utilizado en Chile difiere en varias clases y grupos con relación el catálogo general de cuentas que se lleva en Colombia, en el que resaltan, para el caso chileno, la no aplicación de las clases 6,7 y 8 , lo cual podría generar la no presentación, en forma detallada, de los hechos económicos 
asociados al costo de ventas, los costos de transformación y las cuentas de orden deudoras y acreedoras del ente público.

Es importante expresar que en el resto de las clases y grupos existen unas equivalencias moderadas, salvo en lo relacionado con los pasivos; en el caso colombiano existen siete grupos de cuentas que conforman esta clase; en tanto que el de Chile solamente dispone de tres grupos de cuentas.

En este proceso de convergencia a las Nicsp, la Contaduría General de la Nación, además de la Resolución 620 de 2015, ha expedido el plan único de cuentas para las entidades de educación superior, mediante la Resolución 643 del 16 de diciembre de 2015, las cuales han tenido modificaciones en cuentas y subcuentas mediante las Resoluciones 015 de 2017, relacionada con operaciones interinstitucionales, y 618 del 18 de octubre de 2016, para el caso de las instituciones de educación superior.

Con el fin de contribuir al logro de los objetivos del marco conceptual, adicional al sistema contable es necesario un sistema de costos que permita identificar el valor de los servicios prestados y el manejo de sus recursos, con el fin de presentar información más detallada que les permitirá a los usuarios tomar mejores decisiones frente al cometido del ente público.

\section{Conclusiones}

Entre el marco conceptual de Colombia y Chile existen similitudes en el proceso de implementación de las normas internacionales de contabilidad para el sector público (Nicsp), dado que en Chile se efectuó una adopción indirecta y en Colombia una armonización de las normas.

Las entidades públicas de Colombia y Chile se enmarcan dentro de un entorno jurídico, económico y social que condicionan el Sistema Nacional de Contabilidad Pública (SNCP), para el caso colombiano, y el Sistema de Contabilidad General de la Nación (SCGN), para el chileno.

Las características cualitativas de ambos países difieren en la clasificación que hizo Colombia, dado que las estructuró en una parte como fundamentales y en otra de mejora.

En el deterioro para activos que no generan beneficios económicos y que contribuyen con un potencial de servicios, Colombia adapta dos formas de las establecidas en las Nicsp, como son el costo de reposición a nuevo ajustado por depreciación y el costo de reposición a nuevo ajustado por depreciación y rehabilitación, mientras que el gobierno de Chile adopta tres formas, como son el enfoque del costo de reposición depreciado, el enfoque del costo de rehabilitación y el enfoque de las unidades de servicio.

El modelo instrumental de los dos países presenta diferencias en sus niveles de agrupación del plan de cuentas, no obstante, cada catálogo permite reconocer las operaciones financieras, económicas y sociales que suceden en los gobiernos de Colombia y Chile.

Frente a los avances y desafíos en materia contable, los dos países plantean el fortalecimiento y la modernización de la regulación contable con fundamento en el contexto nacional e internacional para presentar información contable y financiera útil para la toma de decisiones, el control y la rendición de la información a sus diferentes usuarios.

\section{Referencias bibliográficas}

Colmenares, R., Franco, R. y Pulgarín, H. (2008). Evolución del proceso de planificación contable en Colombia. En: Textos de Contabilidad Pública/Contaduría General de la Nación N 5. Bogotá: Imprenta Nacional.

Constitución Política. (1991). Recuperado de https://www.alcaldiabogota.gov.co/sisjur/normas/Norma1.jsp?i=412 5

Constitución Política de la República de Chile. (2010). Recuperado de https://www.oas.org/dil/esp/Constitucion_ Chile.pdf 
Contaduría General de la Nación. (2003). Plan General de Contabilidad Pública. Recuperado de http://entidadpubli ca.co/wp-content/uploads/2013/06/Plan-General-de-Contabilidad-Publica.pdf.

Contaduría General de la Nación. (2007). Plan General de Contabilidad Pública. Recuperado de http://www.contad uria.gov.co/.../rcp2007/plan-contabilidad-publica/.../L2dJQSEvUUt3QS8

Contaduría General de la Nación. (2007). Resolución 355 de 2007. Recuperado de http://www.alcaldiabogota.gov.co /sisjur/normas/Norma1.jsp?i=26678

Contaduría General de la Nación. (2013). Estrategia de convergencia de la regulación contable pública hacia normas internacionales de información financiera (NIIF) y normas internacionales de contabilidad para el sector público (Nicsp). Recuperado de http://www.contaduria.gov.co/.../Estrategia + de+convergencia + de+la + regulación + co ntable+p...pdf.

Contaduría General de la Nación. (2015). Resolución 620 de 2015. Catálogo general de cuentas para entidades de gobierno. Recuperado de http://www.contaduria.gov.co/.../CGC+Versión+2015.01+(Nov+27-2015).pdf

Corte Constitucional de Colombia. (1997). Sentencia C-487 de 1997. Recuperado de http://www.corteconstitucion al.gov.co/relatoría/1997/C-487-97.htm.

Mejía, E., Montes, E. y Montilla, O. (2006). Contaduria internacional. Bogotá: Ecoe Ediciones.

Ministerio de Educación de la República de Colombia. (1990). Ley 43 de 1990. Recuperado de http://www.minedu cacion.gov.co/1759/articles-104547_archivo_pdf.pdf

Senado de la República de Colombia. (1996). Ley 298 de 1996. Recuperado de http://www.secretariasenado.gov.co /senado/basedoc/ley_0298_1996.html

Senado de la República de Colombia. (1998). Ley 489 de 1998. Recuperado de http://www.alcaldiabogota.gov.co/si sjur/normas/Normal.jsp?i=186

Licencia Creative Commons CC BY 4.0

Para citar este artículo: Velásquez Graciano, Ó. D. y Pérez Morales, J. V. (2018). Convergencia a Normas Internacionales de Contabilidad para el Sector Público (Nicsp): comparativo de los modelos de Colombia y Chile. Cuadernos de Contabilidad, 19(47), 24-59. https://doi.org/10.11144/Javeriana.cc18-45.cnic 